\title{
Avaliação da centrífuga rotarex na determinação do teor de ligante e granulometria de diferentes concretos asfálticos
}

\author{
Centrifuge rotarex evaluation in content binder and granulometry determination of \\ different asphalt concrete
}

\section{Bruno César Silva Gonçalves ${ }^{1}$, Deividi da Silva Pereira ${ }^{2}$, Luciano Pivoto Specht ${ }^{3}$, Rinaldo José Barbosa Pinheiro 4}

1Universidade Federal de Santa Maria, Rio Grande do Sul - Brasil, brunocsg@live.com

2Universidade Federal de Santa Maria, Rio Grande do Sul - Brasil, dsp@ufsm.br

3Universidade Federal de Santa Maria, Rio Grande do Sul - Brasil, luspesht@ufsm.br

4Universidade Federal de Santa Maria, Rio Grande do Sul-Brasil, rinaldo@ufsm.br

\section{Recebido:}

18 de setembro de 2018

Aceito para publicação:

17 de abril de 2019

Publicado:

31 de agosto de 2020

Editor de área:

Jorge Barbosa Soares

\section{Palavras-chaves:}

Controle tecnológico.

Misturas asfálticas.

Teor de ligante.

Granulometria.

\section{Keywords:}

Quality assurance.

Asphalt mixture.

Asphalt content.

Granulometric analysis.

DOI:10.14295/transportes.v28i3.1841

\section{RESUMO}

O presente artigo avaliou os procedimentos de determinação de teor de ligante e granulometria de concretos asfálticos, utilizando o método de extração de ligante por centrifugação com o Rotarex. No estudo foram utilizados: faixa B e C do DNIT; 6 diferentes rochas; 3 teores de ligante; CAP 50-70 e AMP 60/85-E-SBS e solvente tricloroetileno, avaliando suas influências nos resultados. Desta maneira, obter o teor de ligante e a granulometria por meio de análise estatística: desvio padrão; erro absoluto e ANOVA. Nessa pesquisa, os teores de ligante obtidos por intermádio da centrífuga revelaram uma baixa confiabilidade. Os valores de desvio padrão e erro absoluto médio extrapolaram o limite de $0,3 \%$ de variação de teor de ligante do DNIT para produção de concretos asfálticos, colocando em dúvida a centrífuga como metodologia a ser utilizada em controle de produção e qualidade. $O$ erro absoluto médio da obtenção de teor de ligante mostrou-se inversamente proporcional ao teor empregado na mistura, impossibilitando um fator de correção para calibração. Esses erros da centrífuga estão diretamente ligados à sua extração ineficiente do ligante asfáltico com uma alta sensibilidade dos seus dados. A análise granulométrica foi igualmente influenciada pela extração incompleta do ligante pela centrífuga, onde o acúmulo de material fino junto ao ligante não extraído em peneiras mais grossas provocou distorções nas curvas granulométricas. Em várias misturas as curvas extrapolaram equivocadamente os limites de trabalho.

\section{ABSTRACT}

This article evaluated the determination of binder content and sieve analysis of asphalt mixtures, using the binder extraction method by Rotarex centrifugation. It was employed in this study two granulometric ranges, six different rocks, three binder contents, CAP 50-70 and $P M B$ 60/85-E-SBS and solvent trichloroethylene, evaluating their influence in the results of binder content and gradation through statistical analysis: standard deviation, absolute error and ANOVA. In this researching, the binder content obtained through centrifugation showed a low liability. The values of standard deviation and absolute error extrapolated the limit of $0.3 \%$ of DNIT binder content variation for the production of asphaltic concretes, questioning the centrifuge as a methodology to be used in production and quality control. The mean absolute error of the binder content showed to be inversely proportional to the employed binder content itself, so it was not possible to achieve a calibration factor. These uncertainties are connected to the inefficient asphalt extraction and a high susceptibility data. The sieve analysis was equally influenced by an incomplete binder extraction by centrifugal, which the fine material accumulation to the non-extracted binder caused distortions to the granulometric analysis. In several mixtures, the curves mistakenly extrapolated the limits of grading. 


\section{INTRODUÇÃO}

O concreto asfáltico passa por várias fases até a sua aplicação no trecho: projeto; caracterização dos materiais; produção; controle de qualidade; execução e controle de aceitação. 0 controle tecnológico está inserido dentro deste ciclo, desencadeando enorme importância. Ele não deve gerar dúvidas em seus valores, já que ele é quem dita à conformidade do pavimento com o seu projeto (Cominsky et al., 1998; Burati et al., 2003). Um equívoco na fase de controle pode gerar dois erros: o primeiro ligado ao produtor, em caso de não aceitação de um material; e o segundo afeta diretamente os usuários da via, em caso de aceitação de um material fora dos limites de projeto (Yoder e Witczak, 1975).

Diversas são as consequências de falha no controle do processo construtivo: baixa estabilidade, baixa resistência ao trincamento por fadiga, corrugação, deformações plásticas, desagregações, baixo atrito pneu/pavimento, oxidação acelerada e permeabilidade excessiva. Ainda, uma correta graduação do concreto asfáltico também garante a rigidez, durabilidade, trabalhabilidade, resistência à fadiga e deformação permanente da mistura (Bernucci et al., 2006; Papagiannakis e Masad, 2008; Harvey et al., 1995; Medina e Motta, 2015).

Existe uma grande dificuldade de empreiteiros em manter sua produção próxima dos valores de projeto e, até mesmo, dentro dos limites de trabalho, onde surge a necessidade de um adequado controle de qualidade a garantir o sucesso de uma obra viária. A variabilidade das características dos insumos é esperada, além da variação na produção e no processo construtivo, por tanto, são estabelecidos limites de aceitação do concreto asfáltico (Yoder e Witczak, 1975; Cominsky et al., 1998; Butts e Ksaibati, 2003; Nogueira, 2011).

Dentro do processo de controle de qualidade e aceitação, encontra-se a metodologia de extração de ligante com solvente com a centrífuga Rotarex (DNER-ME 053/94). Essa, uma metodologia concebida para controle de teor de ligante de misturas asfálticas. Ela se coloca, atualmente, num ponto de necessária revalidação de sua metodologia, visto os inúmeros avanços nas metodologias de dosagem e projeto de pavimentação no Brasil, como o MeDiNa. No início dos anos 1990, nos EUA foi desenvolvido o forno de ignição, com a finalidade de acompanhar o Superpave. Assim, teriam uma metodologia aprimorada de dosagem seguida de um ensaio de extração preciso e confiável, visto que os ensaios de extração de ligante à base de solventes já eram vistos como ultrapassados e pouco confiáveis em diversos departamentos estaduais de transporte (Cipione et al., 1991; Cominsky et al., 1998; Collins-Garcia et al., 2000). Logo, esse avanço na dosagem brasileira de pavimentos deve ser acompanhado de uma metodologia de controle de teor de ligante condizente, justificando a pesquisa em mãos.

Os métodos de extração com solvente são métodos práticos utilizados há mais de um século, sendo mais comumente utilizados os métodos por centrifugação e por refluxo (Brown et al., 1995). Os métodos são baseados na dissolução do ligante asfáltico da mistura asfáltica pela reação com solventes, retirando este resíduo da mistura asfáltica por centrifugação, vácuo ou refluxo. São muitas as desvantagens da utilização desses métodos devido à utilização de solventes, como apontado por Hall e Wilians (1998): ambientalmente hostis; dificuldades devido à periculosidade de utilização (WHO, 1989); manuseio e armazenamento; perda de parcela de agregado mineral fino durante a extração, acarretando em erros no teor de ligante e granulometria (Collins-Garcia et al., 2000).

No passado, vários solventes foram utilizados em procedimentos de extração. 0 dissulfeto de carbono e o benzeno foram muito utilizados como solventes na extração de asfalto. Porém, nas 
décadas de 1950 e 1960 novos solventes clorados surgiram devido à sua toxicidade, surgindo um novo grupo: tricloroetileno; 1,1,1-tricloroetano e cloreto de metileno (Burr et al., 1990a). Estudos já foram realizados com o objetivo de procurar solventes alternativos, como o estudo de Collins-Garcia et al. (2000), além de pesquisas testando diversos solventes para recuperação do asfalto extraído para análise e comparando a eficácia na extração. Dentre eles o tricloroetileno, tricloroetileno com adição de etanol, piridina, clorofórmio, tolueno, benzeno, tetracloreto de carbono, entre outros (Burr et al., 1990b; Cipione et al., 1991).

Atualmente, a ASTM D2172 indica os seguintes solventes: carbonato de amônio; diclorometano; brometo de n-propila e tricloroetileno. Com a proibição do 1,1,1-tricloroetano, o tricloroetileno tornou-se o mais popular e eficaz desses solventes, fazendo parte da norma desde 1981. No entanto, sabe-se que esse pode causar desde dores de cabeça, tonturas, tremores, além de possuir potencial cancerígeno conforme vários órgãos de saúde internacionais e norte americanos, que já trataram publicamente dos níveis de exposição desse solvente (Agency for Toxic Substances and Disease Registry, 2014). Deve-se destacar ainda, que o benzeno e o tetracloreto de carbono são ainda pertencentes à DNER 053/94, porém não são mais utilizados e são vistos dentre os solventes de menor eficácia na extração de asfalto em misturas asfálticas (Cipione et al., 1991).

Mesmo utilizando solventes de maior eficácia, como o tricloroetileno com 15\% de etanol e o propanol, ainda são encontrados resquícios de asfalto não extraído no agregado (Petersen et al., 1974, Petersen, 1982 e Cipione et al., 1991). A parcela de asfalto absorvido pelo agregado possui diferente composição do asfalto efetivo e é de dificil extração (Traxler, 1967 e Plancher et al., 1977). Além disso, cada solvente tem uma predisposição a extrair certas parcelas desse asfalto absorvido, assim, não há um solvente 100\% efetivo (Cipione et al., 1991).

A norma ASTM D2172 deixa claro, em nota, que os métodos de ensaio com solventes nela preconizados não possuem garantia de qualidade de seus resultados. Os desvios padrões e porcentagens de erro absoluto entre ensaios consecutivos são baseados nos dados históricos disponibilizados pela AASHTO, para agências qualificadas pela ASTM D3666. Os usuários da ASTM D2172 são advertidos de que mesmo credenciadas em conformidade com a ASTM D3666, agências e laboratórios não possuem garantia de resultados confiáveis com as extrações com solvente por saber-se da influência de operadores, manutenção do equipamentos e ineficiência desses métodos (ASTM, 2017; Traxler, 1967; Petersen et al., 1974; Petersen, 1982; Petersen, 2000).

O presente artigo procurou avaliar os procedimentos de determinação de teor de ligante e granulometria de concretos asfálticos utilizando o método de centrifugação pelo Rotarex. Com os resultados de extração de ligante asfáltico foram avaliadas as influências de utilização de diferentes faixas granulométricas de concreto asfáltico, diferentes rochas, diferentes teores e diferentes ligantes nos resultados de obtenção de teor de ligante e granulometria.

\section{METODOLOGIA}

0 planejamento da pesquisa consistiu em utilizar 6 rochas de diferentes origens mineralógicas do estado do Rio Grande do Sul empregadas como agregado mineral para a confecção de misturas de concreto asfáltico. Essas sendo enquadradas nas faixas B e C do DNIT, sendo 3 misturas para cada faixa com variações de teor de ligante. Utilizou-se CAP 50-70 para as misturas em todas as rochas, sendo que para uma das rochas, também, foi empregado asfalto modificado por polímero (AMP 60/85-E SBS) para fins de comparação. 
Na Figura 1 encontra-se a localização das cidades de origem dos agregados da pesquisa e suas regiões geomorfológicas. Para caracterização dos agregados (Tabela 1) foram utilizados os seguintes ensaios normatizados: Absorção (DNER-ME 195/97 e NBR 30/2001); Massa específica (DNER-ME 195/97); Sanidade (DNER-ME 089/94) e Perda a abrasão LA (DNER-ME 035/98).

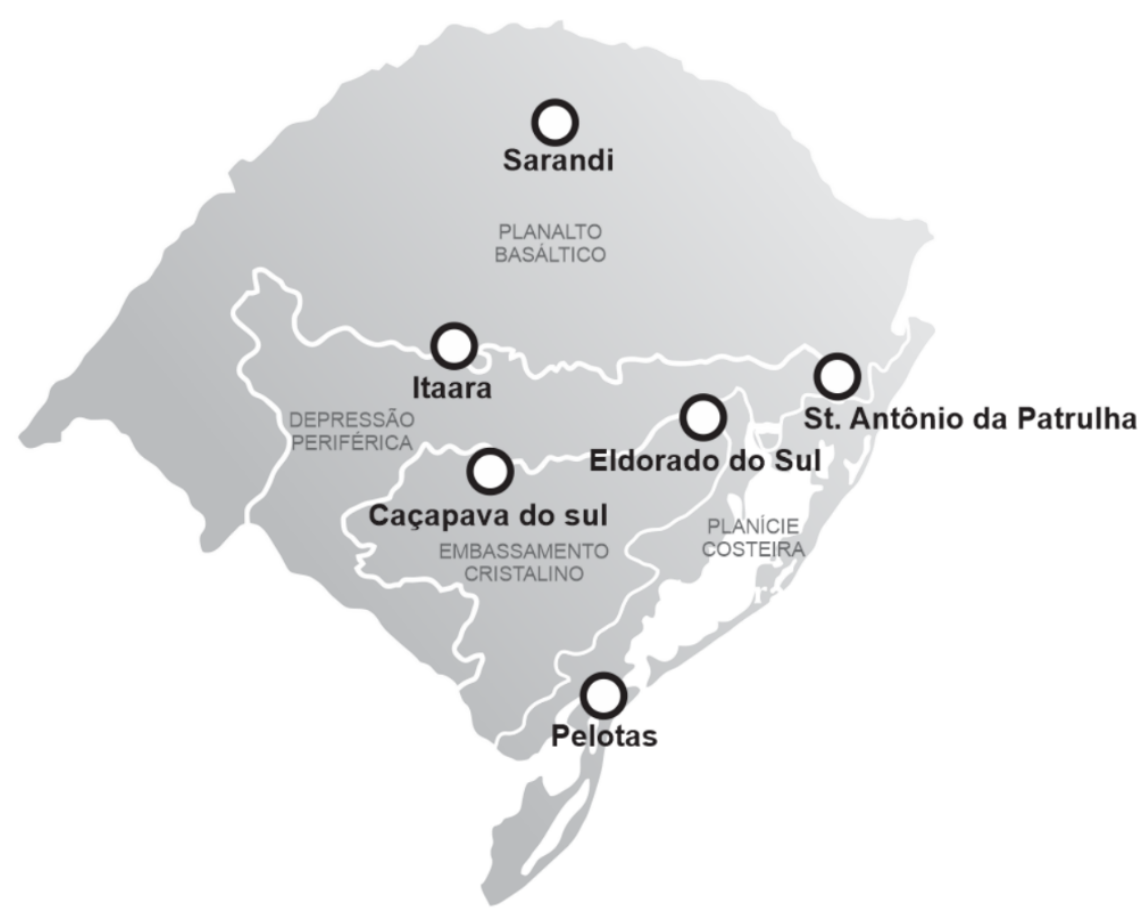

Figura 1. Localização das cidades de origem dos agregados da pesquisa

Tabela 1 - Resumo das características de cada rocha da pesquisa

\begin{tabular}{|c|c|c|c|c|c|c|}
\hline & $\begin{array}{l}\text { Classificação } \\
\text { petrográfica }\end{array}$ & Agregado & $\begin{array}{c}\text { Absorção } \\
\text { (\%) }\end{array}$ & $\begin{array}{c}\text { Massa } \\
\text { Específica real } \\
\left(\mathrm{g} / \mathrm{cm}^{3}\right)\end{array}$ & $\begin{array}{c}\text { Perda por } \\
\text { abrasão (\%) }\end{array}$ & Sanidade (\%) \\
\hline \multirow{2}{*}{ Santo Ant. da Patrulha } & \multirow{2}{*}{ Diabásio } & Graúdo & 0,978 & 2,825 & 9,88 & 3,47 \\
\hline & & Miúdo & 0,864 & 2,696 & --- & --- \\
\hline \multirow{2}{*}{ Itaara } & \multirow{2}{*}{ Riodacito } & Graúdo & 3,126 & 2,658 & 10,67 & 1,521 \\
\hline & & Miúdo & 3,551 & 2,569 & ---- & --- \\
\hline \multirow{2}{*}{ Sarandi } & \multirow{2}{*}{ Diabásio } & Graúdo & 1,683 & 2,995 & 16,87 & 1,22 \\
\hline & & Miúdo & 1,906 & 2,965 & --- & --- \\
\hline \multirow{2}{*}{ Eldorado do Sul } & \multirow{2}{*}{$\begin{array}{l}\text { Metasieno } \\
\text { Granito }\end{array}$} & Graúdo & 0,624 & 2,633 & 21,3 & 0,636 \\
\hline & & Miúdo & 0,634 & 2,501 & --- & --- \\
\hline \multirow{2}{*}{ Pelotas } & \multirow{2}{*}{$\begin{array}{c}\text { Sieno } \\
\text { Granito }\end{array}$} & Graúdo & 1,187 & 2,638 & 21,30 & 10,7 \\
\hline & & Miúdo & --- & 2,662 & --- & --- \\
\hline \multirow{2}{*}{ Caçapava do Sul } & \multirow{2}{*}{$\begin{array}{l}\text { Mármore } \\
\text { Dolomítico }\end{array}$} & Graúdo & 0,429 & 2,839 & 14,79 & 4,32 \\
\hline & & Miúdo & 0,566 & 2,831 & --- & --- \\
\hline
\end{tabular}

A caracterização dos ligantes utilizados na pesquisa, CAP 50-70 e AMP 60/85-E SBS, está indicada na Tabela 2. Os ensaios do CAP 50-70 foram realizados pelos autores e do AMP 60/85E-SBS por Bohn (2017). 
Tabela 2 - Caracterização dos ligantes

\begin{tabular}{llcccc}
\hline & & \multicolumn{2}{c}{ CAP 50-70 } & \multicolumn{2}{c}{ AMP 60/85-E-SBS } \\
\hline PROPRIEDADE & Norma & Limites & Resultado & Limites & Resultado \\
\hline Penetração $(0,1 \mathrm{~mm})$ & NBR 6576:2007 & 50 a 70 & 62 & 40 a 70 & 65 \\
\hline Ponto de Amol. $\left({ }^{\circ} \mathrm{C}\right)$ & NBR 6560:2016 & $\geq 46$ & 48 & $\geq 60$ & 64 \\
\hline $\begin{array}{l}\text { Viscosidade Brookfield } \\
135^{\circ} \mathrm{C} \text { (Pa.s) }\end{array}$ & NBR 15184:2004 & $\geq 274$ & 335 & $\leq 3.000,0$ & 1247 \\
\hline $\begin{array}{l}\text { Viscosidade Brookfield } \\
150^{\circ} \mathrm{C} \text { (Pa.s) }\end{array}$ & NBR 15184:2004 & $\geq 112$ & 160 & $\leq 2.000,0$ & 659 \\
\hline $\begin{array}{l}\text { Viscosidade Brookfield } \\
177^{\circ} \mathrm{C} \text { (Pa.s) }\end{array}$ & NBR 15184:2004 & 57 a 285 & 65 & $\leq 1.000,0$ & 240 \\
\hline Recuperação elástica (\%) & NBR 15086:2006 & --- & --- & $\geq 85$ & 86,5 \\
\hline Ponto de Fulgor $\left({ }^{\circ} \mathrm{C}\right)$ & NBR 11341:2014 & 235 min & --- & 235 min & 235 min \\
\hline Densidade relativa & NBR 6296:2012 & --- & 1,005 & --- & 1,011 \\
\hline
\end{tabular}

\subsection{Dosagens e preparação das misturas}

Nesta pesquisa optou-se pela dosagem Marshall (DNER - ME 043/95) para melhor reproduzir a metodologia de dosagem aplicada na prática, com o emprego do Rice Test (NBR 15619:2016) na determinação da massa específica máxima teórica. Além disso, utilização da norma ABNT NBR16273:2014 para os cálculos das propriedades volumétricas dos concretos asfálticos. Os dados das misturas podem ser vistos na Tabela 3, onde: Pba é a absorção de asfalto pelo agregado, sendo a razão entre a massa de ligante asfáltico absorvida pelo agregado e a massa total dos agregados, expressa em porcentagem (ABNT NBR16273:2014); Absorção ponderada é a absorção da mistura calculada através das proporções de agregado graúdo e miúdo na mistura.

Todos os agregados foram separados por peneira no laboratório, possibilitando que todas as misturas ficassem no centro da faixa B e C do DNIT (Figura 2).

Como critério de dosagem foi escolhido o método sugerido por Ceratti e Reis (2011), no qual é obtido o teor de ligante mediante um método gráfico a partir dos valores de Vv e RBV em função do teor de ligante dos CPs.

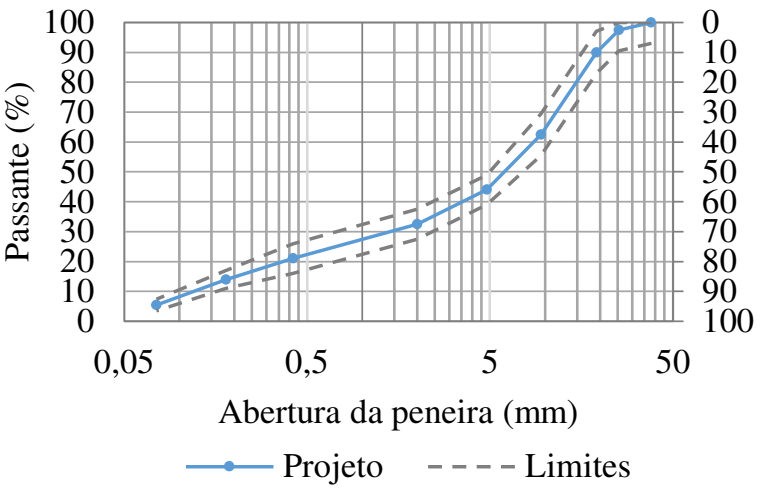

a)

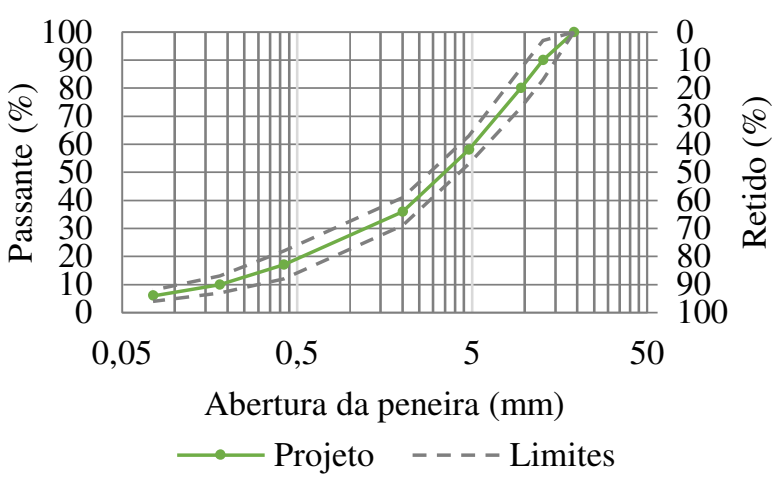

b)

Figura 2. Composição granulométrica - Faixa B (a) e Faixa C (b) do DNIT 031/2006 - ES 
Para cada rocha foram realizadas 2 dosagens, uma para a faixa $\mathrm{B}$ e uma para a faixa C do DNIT (Tabela 3). Foram realizadas 3 misturas para cada faixa, uma no teor de projeto, uma com redução de 0,5\% e outra com adição de 0,5\% do teor de ligante. De cada mistura foram confeccionadas 5 amostras com cerca de $600 \mathrm{~g}$, capacidade da centrífuga disponível para a pesquisa. Assim, as quantidades totais de amostras foram: 14 dosagens; 42 misturas (21 para cada faixa); totalizando 210 amostras, ou seja, 210 extrações seguidas de 210 análises granulométricas.

Tabela 3 - Resumos dos dados de dosagem (CAP 50-70 e AMP 60/85-E SBS)

\begin{tabular}{|c|c|c|c|c|c|c|c|c|c|c|}
\hline $\begin{array}{l}\text { Origem e } \\
\text { Classificação petrográfica }\end{array}$ & Faixa & $G m m^{2}$ & $\mathrm{Gse}^{4}$ & $\mathbf{G s b}^{4}$ & $\begin{array}{l}\text { Absorção } \\
\text { Ponderada }{ }^{3} \\
\text { (\%) }\end{array}$ & $\begin{array}{l}\text { Vv } \\
\text { (\%) }\end{array}$ & $\begin{array}{l}\text { RBV } \\
\text { (\%) }\end{array}$ & $\begin{array}{l}E \\
\text { (N) }\end{array}$ & $\begin{array}{l}\mathrm{Pba}^{4} \\
(\%)\end{array}$ & $\begin{array}{l}\text { Teor de } \\
\text { Projeto } \\
\text { (\%) }\end{array}$ \\
\hline Santo Ant. da Patrulha & $B$ & 2,540 & 2,732 & 2,717 & 0,91 & 3,4 & 77 & 1.050 & 0,20 & 4,90 \\
\hline Diabásio & $\mathrm{C}$ & 2,525 & 2,686 & 2,682 & 0,89 & 4,0 & 78 & 900 & 0,06 & 5,30 \\
\hline Santo Ant. da Patrulha ${ }^{1}$ & $B$ & 2,538 & 2,732 & 2,717 & 0,91 & 3,4 & 77 & 1.100 & 0,20 & 4,80 \\
\hline Diabásio & $C$ & 2,517 & 2,686 & 2,682 & 0,89 & 4,0 & 78 & 920 & 0,06 & 5,00 \\
\hline Itaara & $\mathrm{B}$ & 2,365 & 2,565 & 2,523 & 3,38 & 4,1 & 78 & 1.250 & 0,65 & 5,90 \\
\hline Riodacito & $\mathrm{C}$ & 2,335 & 2,567 & 2,546 & 3,47 & 4,3 & 77 & 1.100 & 0,32 & 7,00 \\
\hline Sarandi & B & 2,655 & 2,878 & 2,845 & 1,82 & 3,7 & 76 & 1.450 & 0,41 & 5,10 \\
\hline Diabásio & C & 2,635 & 2,864 & 2,848 & 1,86 & 3,7 & 79 & 1.200 & 0,20 & 5,50 \\
\hline Eldorado & B & 2,397 & 2,641 & 2,632 & 0,63 & 3,5 & 78 & 1.050 & 0,13 & 5,40 \\
\hline Metasieno Granito & $\mathrm{C}$ & 2,390 & 2,638 & 2,633 & 0,63 & 3,7 & 76 & 1.150 & 0,07 & 5,70 \\
\hline Pelotas & $\mathrm{B}$ & 2,425 & 2,589 & 2,586 & 1,19 & 3,5 & 78 & 1.300 & 0,05 & 5,30 \\
\hline Sieno Granito & $\mathrm{C}$ & 2,385 & 2,577 & 2,575 & 1,20 & 3,5 & 78 & 980 & 0,03 & 5,70 \\
\hline Caçapava & $B$ & 2,620 & 2,779 & 2,774 & 0,51 & 3,5 & 77 & 950 & 0,07 & 5,10 \\
\hline Mármore Dolomítico & C & 2,595 & 2,772 & 2,770 & 0,53 & 3,4 & 80 & 850 & 0,03 & 4,80 \\
\hline
\end{tabular}

${ }^{1}$ Misturas com AMP 60/85-E SBS

${ }^{2}$ Densidade máxima medida obtida pelo Rice Test (ABNT NBR 15619:2016)

${ }^{3}$ Relativa às porcentagens de agregado graúdo e miúdo, conforme valores da Tabela 1

4Propriedades volumétricas obtidas através da norma ABNT NBR16273:2014

Realizou-se uma única mistura em um misturador mecânico para cada traço proposto, assim, as 5 amostras de uma mesma mistura foram retiradas de uma única batelada. Ressalta-se que as misturas foram realizadas em ambiente laboratorial totalmente controlado. As amostras foram coletadas em bandejas direto do misturador, sem qualquer compactação.

\subsection{Método de extração com a centrífuga e análise granulométrica}

Os ensaios de extração foram realizados somente com o modelo de centrífuga elétrica, conhecida por Rotarex, e seguindo as indicações da norma DNER-ME 053/94. Este ensaio é baseado nas normas norte americanas ASTM D2172-75 e AASHTO 164-86, que contemplam diversos extratores com base em solventes. Na norma DNER-ME 053/94 são encontrados detalhes necessários para o ensaio: temperaturas para devida preparação das amostras; tipos de solvente para diferentes tipos de ligante (alguns desses solventes não são mais disponíveis ou são de difícil acesso no mercado); detalhes quanto ao manuseio da amostra antes e depois do ensaio e equação para aferição do teor de ligante na mistura asfáltica.

O solvente utilizado foi o tricloroetileno, fornecido comercialmente como Solver 87 pela empresa LM Química Industrial Ltda. de Alvorada - RS. 0 tricloroetileno é frequentemente utilizado por laboratórios em substituição ao tetracloreto de carbono da DNER-ME 053/94 e é um dos solventes indicados nas normas ASTM D2172 de 2017 e pela norma do extrator soxhlet DNIT 158/2011-ME. A análise granulométrica (DNER-ME 083/98) foi realizada com as amostras secas após extração de ligante. 
Após a coleta, as amostras ficaram em temperatura ambiente até o ensaio no dia seguinte ao processo de mistura. No dia da extração de ligante, as amostras ficaram 1 hora em estufa à $110^{\circ} \mathrm{C}$ para destorroamento (média da faixa de temperatura indicada na DNER-ME 053/94). Logo após, as amostras foram destorroadas e pesadas no prato da centrífuga. Posteriormente a pesagem, o material foi coberto totalmente por solvente e, após $15 \mathrm{~min}$, a centrífuga foi fechada já com o papel filtro. A centrifugação iniciou-se e, assim que o solvente previamente colocado na amostra tivesse sido totalmente extraído, foi adicionado mais $200 \mathrm{ml}$ do diluente, em passos idênticos, até que o solvente saísse límpido, exatamente como preconizado pela norma DNER 053/94. Não foi realizada inspeção visual sobre a amostra acondicionada no equipamento durante o ensaio a fim de seguir exatamente a metodologia corrente no Brasil.

Iniciada a centrifugação, nas condições mencionadas anteriormente, fez-se uma inspeção visual em cada uma das amostras. Nessas observou-se, em alguns casos, a presença de material pétreo mais escurecido, demonstrando uma possível tendência de extração incompleta do ligante. Como essa inspeção não é parte da metodologia normatizada, as amostras não passaram por nova centrifugação. Logo, uma vez que se buscou a implementação do processo de controle de teor de ligante e granulometria idêntico ao estado da prática, empregando-se como critério de parada do ensaio a cor do solvente idêntica à original. Os efeitos decorrentes desse critério de parada configuram-se como objetivos deste trabalho.

0 material resultante com filtro do ensaio de extração foi levado à estufa por $24 \mathrm{~h}$ até constância de massa, em uma temperatura de $90^{\circ} \mathrm{C}$, média indicada por norma. Utilizou-se dos dados obtidos "peso do betume extraído" e "peso da amostra total" para o cálculo de "P", sendo $\mathrm{P}$ a porcentagem de ligante asfáltico. Com a amostra já seca foi realizada a análise granulométrica para cada amostra.

\subsection{Análise dos dados}

Os resultados de teor de ligante e granulometria passaram pelo processo de análise de variância (ANOVA) a partir dos dados de erro absoluto médio (EAM), que é a diferença entre o valor medido e o valor real. Ressalta-se que o limite de variação de teor de ligante de $0,3 \%$ do Manual do DNIT é um limite de erro absoluto (DNIT, 2006). Assim, foi escolhida a ANOVA, um teste de significância baseado na tabela de distribuição $\mathrm{F}$, por ser adequada à matriz do trabalho, com todas as análises utilizando 95\% de confiabilidade. Deste modo, quando o valor P for menor que 0,005 (5\%) o fator estudado é significativo nos resultados.

Os parâmetros Gmm, absorção ponderada, abrasão LA, sanidade e asfalto absorvido passaram por análise de correlação de Pearson aos dados de EAM, com a finalidade de encontrar algum grau de associação entre esses e o erro absoluto dos dados de teor de ligante da centrífuga.

Sequencialmente, foi utilizado o número de Vogt, um método para determinação da superfície específica de curvas granulométricas, para melhor descrever a granulometria antes e após extração. Assim, não se concentrando somente nas curvas, optou-se por analisar a superfície específica das amostras por serem alusivas à maior ou menor finura resultante da distribuição da granulometria. 


\section{RESULTADOS E DISCUSSÕES}

\subsection{Teor de ligante}

Na Tabela 4 são apresentados os dados médios de teor de ligante obtidos com a centrífuga Rotarex. Os dados foram organizados por diferentes faixas granulométricas, diferentes rochas e diferentes teores. Os valores em vermelho extrapolaram o limite de $0,3 \%$ para variação na produção de teor de ligante requerido pelo DNIT para concretos asfálticos, ou seja, esses valores provocariam conclusões equivocadas no controle tecnológico por ter dispersão e erro absoluto maiores do que esse limite. Os dados gerados pela metodologia deveriam apresentar no mínimo valores com dispersão e erro absoluto abaixo de $0,3 \%$. Por exemplo, a mistura Sarandi faixa B com 4,60\% de teor de ligante (produzida com 0,5\% abaixo do teor de referência 5,10\%) apresentou média final na extração de 5,15\% e equivocadamente a mistura seria aprovada, mesmo sendo confeccionada com teor baixo. Além disso, os valores elevados de desvio padrão conjunto ao erro absoluto demonstram que não há garantia de que o teor médio encontrado seja representativo da mistura ensaiada.

Tabela 4 - Médias de 5 determinações de teor de ligante

\begin{tabular}{|c|c|c|c|c|c|c|c|c|c|}
\hline \multirow[b]{2}{*}{$\begin{array}{l}\text { Origem e } \\
\text { classificação } \\
\text { petrográfica }\end{array}$} & \multirow[b]{2}{*}{ Ligante } & \multicolumn{4}{|c|}{ Faixa B } & \multicolumn{4}{|c|}{ Faixa C } \\
\hline & & $\begin{array}{c}\text { Teor } \\
\text { real da mistura } \\
(\%)\end{array}$ & $\begin{array}{c}\text { Teor da } \\
\text { extração } \\
(\%)\end{array}$ & $\sigma^{1}$ & $E A M^{2}$ & $\begin{array}{c}\text { Teor } \\
\text { real da mistura } \\
(\%)\end{array}$ & $\begin{array}{c}\text { Teor da } \\
\text { extração } \\
(\%)\end{array}$ & $\sigma^{1}$ & $E A M^{2}$ \\
\hline \multirow{3}{*}{$\begin{array}{l}\text { Santo Ant. da Patrulha } \\
\text { (Diabásio) }\end{array}$} & \multirow{3}{*}{$\begin{array}{l}\text { CAP } \\
50 / 70\end{array}$} & 4,40 & 5,23 & 0,52 & 0,83 & 4,80 & 6,09 & 0,38 & 1,29 \\
\hline & & 4,90 & 5,41 & 0,48 & 0,51 & $5,30^{1}$ & 6,11 & 0,09 & 0,81 \\
\hline & & 5,40 & 4,98 & 0,32 & $-0,42$ & 5,80 & 6,07 & 0,29 & 0,27 \\
\hline \multirow{3}{*}{$\begin{array}{l}\text { Santo Ant. da Patrulha }{ }^{2} \\
\text { (Diabásio) }\end{array}$} & \multirow{3}{*}{$\begin{array}{l}\text { AMP } \\
60-85\end{array}$} & 4,30 & 4,82 & 0,41 & 0,52 & 4,50 & 5,37 & 0,13 & 0,87 \\
\hline & & 4,80 & 5,00 & 0,17 & 0,20 & $5,00^{1}$ & 5,31 & 0,30 & 0,31 \\
\hline & & 5,30 & 4,35 & 0,36 & $-0,95$ & 5,50 & 5,99 & 0,28 & 0,49 \\
\hline \multirow{3}{*}{$\begin{array}{l}\text { Itaara } \\
\text { (Riodacito) }\end{array}$} & \multirow{3}{*}{$\begin{array}{l}\text { CAP } \\
50 / 70\end{array}$} & 5,40 & 5,87 & 0,25 & 0,47 & 6,50 & 6,58 & 0,35 & 0,08 \\
\hline & & 5,90 & 6,12 & 0,75 & 0,22 & $7,00^{1}$ & 6,93 & 0,26 & $-0,07$ \\
\hline & & 6,40 & 6,16 & 0,36 & $-0,24$ & 7,50 & 7,39 & 0,47 & $-0,11$ \\
\hline \multirow{3}{*}{$\begin{array}{l}\text { Sarandi } \\
\text { (Diabásio) }\end{array}$} & \multirow{3}{*}{$\begin{array}{l}\text { CAP } \\
50 / 70\end{array}$} & 4,60 & 5,15 & 0,43 & 0,55 & 5,00 & 5,36 & 0,51 & 0,36 \\
\hline & & 5,10 & 5,44 & 0,56 & 0,34 & $5,50^{1}$ & 5,74 & 0,51 & 0,24 \\
\hline & & 5,60 & 5,17 & 0,75 & $-0,43$ & 6,00 & 5,82 & 0,62 & $-0,18$ \\
\hline \multirow{3}{*}{$\begin{array}{l}\text { Eldorado } \\
\text { (Metasieno Granito) }\end{array}$} & \multirow{3}{*}{$\begin{array}{l}\text { CAP } \\
50 / 70\end{array}$} & 4,90 & 5,15 & 0,35 & 0,25 & 5,20 & 5,60 & 0,20 & 0,40 \\
\hline & & 5,40 & 5,20 & 0,17 & $-0,20$ & $5,70^{1}$ & 5,95 & 0,48 & 0,25 \\
\hline & & 5,90 & 5,31 & 0,29 & $-0,59$ & 6,20 & 6,16 & 0,52 & $-0,04$ \\
\hline \multirow{3}{*}{$\begin{array}{l}\text { Pelotas } \\
\text { (Sieno Granito) }\end{array}$} & \multirow{3}{*}{$\begin{array}{l}\text { CAP } \\
50 / 70\end{array}$} & 4,80 & 5,16 & 0,73 & 0,36 & 5,20 & 5,49 & 0,18 & 0,29 \\
\hline & & 5,30 & 5,25 & 0,53 & $-0,05$ & $5,70^{1}$ & 5,90 & 0,22 & 0,20 \\
\hline & & 5,80 & 5,62 & 0,49 & $-0,18$ & 6,20 & 6,41 & 0,29 & 0,21 \\
\hline \multirow{3}{*}{$\begin{array}{l}\text { Caçapava } \\
\text { (Mármore Dolomítico) }\end{array}$} & \multirow{3}{*}{$\begin{array}{l}\text { CAP } \\
50 / 70\end{array}$} & 4,60 & 4,99 & 0,30 & 0,39 & 4,30 & 5,22 & 0,10 & 0,92 \\
\hline & & 5,10 & 5,10 & 0,42 & 0,00 & $4,80^{1}$ & 6,01 & 0,22 & 1,21 \\
\hline & & 5,60 & 5,36 & 0,49 & $-0,24$ & 5,30 & 6,20 & 0,64 & 0,90 \\
\hline
\end{tabular}

${ }^{1}$ Desvio padrão

"Erro absoluto médio: diferença entre "Teor da extração" e "Teor da mistura"

${ }^{3}$ Valores em vermelho demonstram que os dados gerados pela centrífuga extrapolam o limite de $0,3 \%$ de variação de teor de ligante na produção, assim, gerando conclusões equivocadas no controle tecnológico.

Então, optou-se por não excluir amostras para que o trabalho chegasse a resultados que refletissem a metodologia. Das 42 misturas, somente 14 misturas apresentaram desvio padrão abaixo de 0,3\% e 21 misturas com EAM abaixo desse mesmo valor. 0 EAM da centrífuga tem origem em alguns fatos que se sobrepõe: a perda de material fino conjunto ao ligante durante a centrifugação (provocando o erro com valor positivo quando ocorre em excesso); a ineficácia da extração total de ligante (provocando o erro negativo quando existe excesso de ligante) e a sensibilidade do ensaio a pequenas variações na ordem de $1 \mathrm{~g}$. 
Deve-se ressaltar que as amostras foram confeccionadas com $600 \mathrm{~g}$ e que erros de apenas $1 \mathrm{~g}$, por exemplo, são suficientes para variar o teor de ligante em quase $0,20 \%$. Isso significa que $1 \mathrm{~g}$ de sensibilidade é um valor muito baixo para um ensaio rudimentar, do qual apresenta condição de término baseada unicamente na avaliação visual do operador. A metodologia também é aberta a inúmeros erros durante a operação, tais como quantidades diferentes de solvente por amostra, tempo de centrifugação não fixado, perda de material passante na $\mathrm{n} \mathbf{0} 200$, asfalto absorvido não extraído, etc.

A baixa qualidade dos resultados da extratora centrífuga é assinalada por diversos autores e observada em nota dentro da norma norte-americana ASTM D2172. Nela, também, são demonstrados dados médios históricos da AASHTO de desvio padrão e diferença entre extrações consecutivas das agências e laboratórios qualificados pela ASTM D3666: desvio padrão de 0,21\% e diferença entre ensaios consecutivos de 0,59\% para agregados com absorção menor que $1,25 \%$, e desvio padrão de $0,30 \%$ e diferença entre ensaios consecutivos de $0,85 \%$ para absorção maior que 2,5\%. Mas, estes dados também são elevados e a norma não dá garantia que mesmo estes laboratórios gerem dados de qualidade com essa metodologia por reconhecer que esses métodos são falhos (Traxler, 1967; Petersen et al., 1974; Petersen, 1982; Petersen, 2000; ASTM, 2017). Recordando que os dados da Tabela 4 são médias de 5 extrações consecutivas e que nenhum dado foi expurgado, procurando mostrar a realidade da metodologia. As extrações com a Faixa C apresentaram os menores valores de desvio padrão, diferentemente da faixa B que somente 5 misturas ficaram abaixo de 0,30\% de desvio padrão.

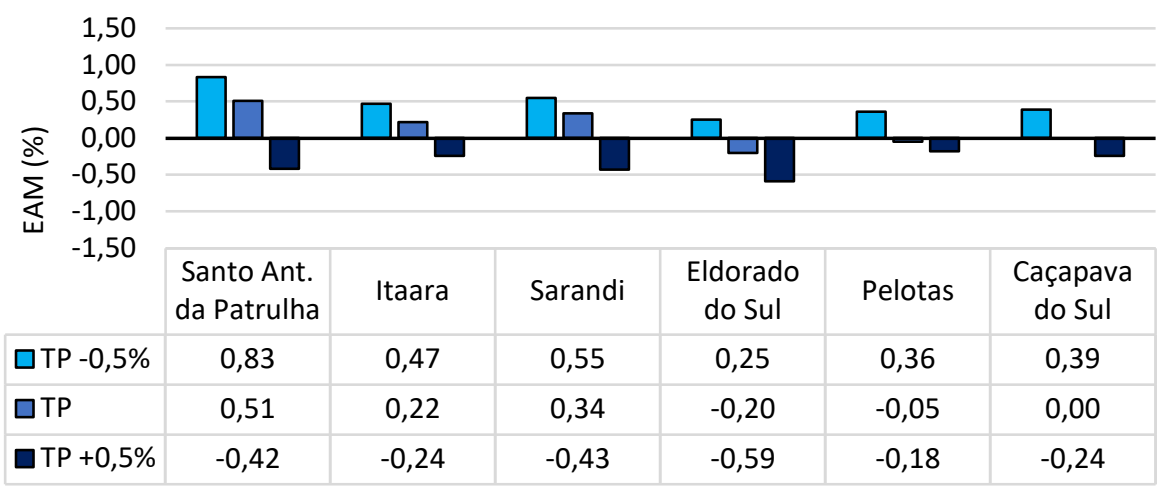

Figura 3. Erro absoluto médio - Teor de ligante - Faixa B

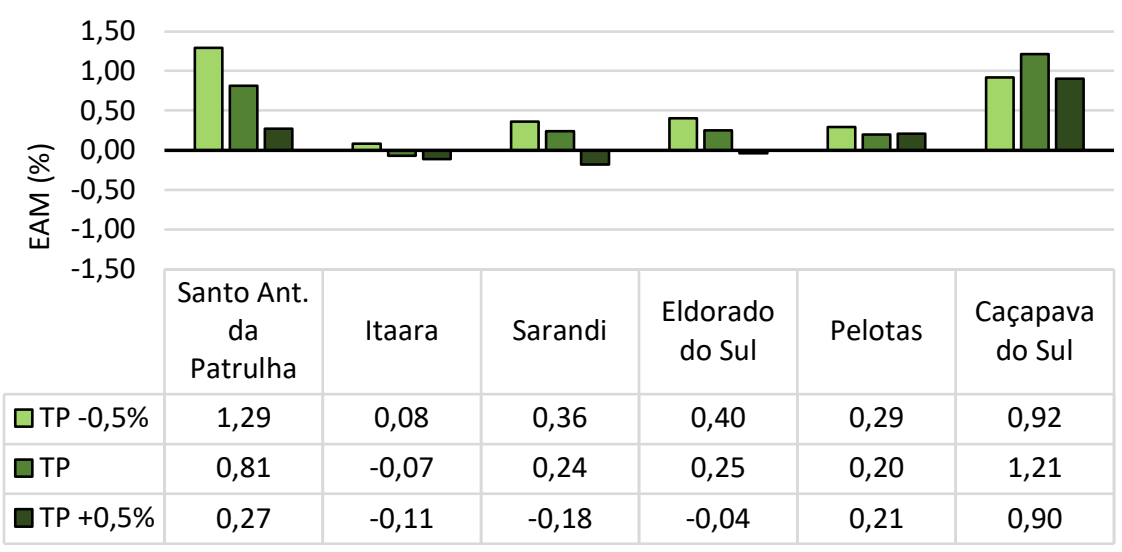

Figura 4. Erro absoluto médio - Teor de ligante - Faixa $C$ 
O segundo ponto a ser destacado foi o padrão encontrado no EAM dos resultados de teor de ligante. Nos gráficos das Figura 3 e Figura 4 observa-se que o teor de ligante da mistura e o EAM mostraram-se inversamente proporcionais, com únicas exceções das misturas na Faixa $\mathrm{C}$ de Caçapava do Sul e Pelotas, todas com EAM positivos. Nas condições de contorno do presente estudo, observa-se a impossibilidade da centrífuga indicar uma variação real de teor de ligante de uma mistura, visto que seus resultados finais se mostraram inversos à real variação de teor empregado nas misturas.

O EAM da centrífuga não se mostrou constante diante das variações de teor de ligante das misturas, logo, um valor único de calibração obtido através desse erro para uma dada mistura não seria capaz de corrigir o valor de erro em caso de variação. Ao utilizar os valores da Tabela 4, nas misturas da faixa C de Sarandi, o valor de calibração seria $-0,24 \%$, baseado no EAM da mistura com teor de projeto (5,50\%), por exemplo. Aplicando este valor de $-0,24 \%$ na mistura TP $+0,5 \%$ de Sarandi (6,00\%), indicaria um teor de 5,58\% (valor médio obtido de 5,82\% descontando os $0,24 \%$ da calibração). 0 valor de $5,58 \%$ de teor de ligante geraria uma conclusão errônea de que a mistura estaria somente $0,08 \%$ fora do projeto, sendo que na realidade ela está $0,50 \%$ acima do teor projetado.

Ainda, foi aplicada ANOVA nos dados de teor de ligante e granulometria. Esta análise foi aplicada com intuito de avaliar se haveria ou não a influência significativa dos diversos fatores nos dados finais de teor de ligante obtidos com a centrífuga.

Como supramencionado, as misturas foram preparadas com diferentes teores de ligante, duas faixas granulométricas faixa B e C, uso de 6 diferentes rochas e 2 tipos de ligante. 0 nível de 95\% de confiabilidade foi utilizado em todas as avaliações, logo, se o valor-p $\leq 0,05$, haverá confirmação de influência significativa do parâmetro avaliado nos dados.

A ANOVA do EAM na obtenção de teor de ligante (Tabela 5) mostrou que o EAM é apenas insensível ao tipo de agregado empregado na faixa B do DNIT. Entretanto, o restante das variações se mostrou significativas nos resultados finais de EAM da centrífuga, para ambas faixas utilizadas no trabalho. Em outras palavras, o EAM é sensível aos parâmetros: tipo de rocha, teor de ligante, tipo de ligante e faixa granulométrica. Esse é um fato preocupante, já que a principal função da centrífuga é ser aplicada como ferramenta no controle tecnológico, logo, seus dados deveriam ter se mostrado com maior isenção de influências dessas variações nas misturas.

Tabela 5 - ANOVA aplicado ao EAM de obtenção de teor de ligante - 95\% de confiabilidade

\begin{tabular}{|c|c|c|c|c|c|c|c|c|c|c|c|c|}
\hline & \multicolumn{4}{|c|}{ Geral } & \multicolumn{4}{|c|}{ Faixa B } & \multicolumn{4}{|c|}{ Faixa C } \\
\hline & $g l$ & $F$ & valor-p & Sig. & $g l$ & $F$ & valor-p & Sig. & $g l$ & $F$ & valor-p & Sig. \\
\hline Rochas & 5 & 5,886 & 0,000 & $S$ & 5 & 1,342 & 0,257 & $N$ & 5 & 13,552 & 0,000 & $S$ \\
\hline Teor de ligante & 2 & 23,148 & 0,000 & $S$ & 2 & 17,624 & 0,000 & $S$ & 2 & 6,088 & 0,004 & $S$ \\
\hline Tipo de Ligante & 1 & 5,457 & 0,023 & $S$ & 1 & 26,091 & 0,000 & $S$ & 1 & 4,766 & 0,039 & $S$ \\
\hline Faixa & 1 & 13,714 & 0,000 & $S$ & & & & & & & & \\
\hline onde: & & $\begin{array}{l}\text { gra } \\
\text { razã } \\
\text { pro } \\
\text { Sigr }\end{array}$ & $\begin{array}{l}\text { de liberdac } \\
\text { entre a var } \\
\text { bilidade de } \\
\text { cância (S) }\end{array}$ & $\begin{array}{l}\text { dos gr } \\
\text { ncia el } \\
\text { ignific } \\
\text { não si }\end{array}$ & $\begin{array}{l}\text { cia } \\
\text { nificâ }\end{array}$ & $\begin{array}{l}\text { 1) } \\
\text { upos pela } \\
\text { ia }(\mathrm{N}) \text { do }\end{array}$ & $\begin{array}{l}\text { riância de } \\
\text { or testado }\end{array}$ & o dos & 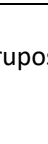 & a distrib & o F & \\
\hline
\end{tabular}

Regressão linear foi aplicada nos dados de obtenção de teor de ligante em função do teor realmente empregado nas misturas (Figura 5). Devido à alta dispersão dos resultados, o valor de $\mathrm{R}^{2}$ ficou em somente 0,56 , valor considerado baixo e que demonstra a baixa acurácia e precisão dos dados de teor de ligante obtidos com a centrífuga. 
Seguindo a análise estatística, na tabela 6, observa-se que não há uma correlação considerável entre as propriedades testadas das rochas e misturas com o EAM de teor de ligante encontrado, sendo de muito fraca a desprezível pela análise de correlação de Pearson. 0 coeficiente $\rho$ da correlação de Pearson indica o grau e direção de correlação entre duas variáveis, com o intervalo de +1 a -1 .

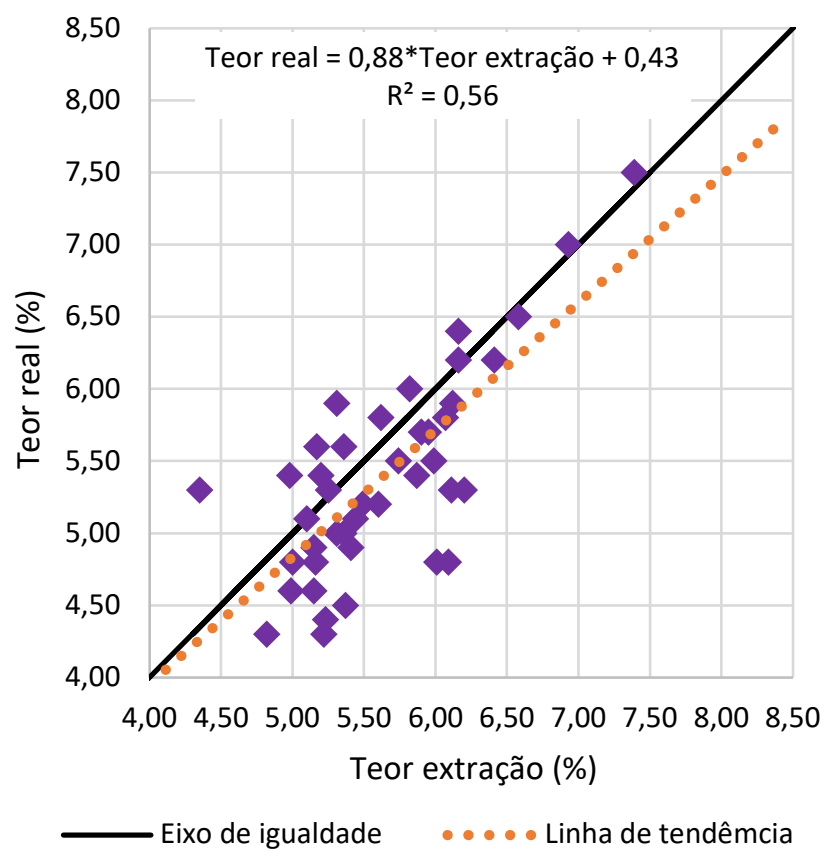

Figura 5. Regressão linear dos dados médios de obtenção de teor de ligante

Tabela 6 - Análise de correlação de Pearson entre propriedades das rochas e misturas e o EAM de teor de ligante

\begin{tabular}{lll}
\hline Parâmetro & $\boldsymbol{\rho}$ & Correlação \\
\hline Gmm & 0,189 & Muito fraca \\
Absorção ponderada & $-0,168$ & Muito fraca \\
Abrasão LA & $-0,183$ & Muito fraca \\
Sanidade & 0,057 & Desprezível \\
Asfalto absorvido & -0.157 & Muito fraca \\
\hline
\end{tabular}

Na Tabela 6 foi visto que não há correlação entre $G m m$, absorção ponderada, abrasão LA, sanidade ou asfalto absorvido com o EAM, mas na Tabela 5 o uso de diferentes rochas se mostra significativo no EAM do teor de ligante. Essa significância provavelmente é ligada a outras propriedades das rochas que não foram avaliadas no presente estudo, como nível de acidez, ligada à adesividade entre rocha e ligante, lamelaridade, ligada a superfície específica dos agregados, etc.

\subsection{Análise Granulométrica}

São apresentadas as análises granulométricas das faixas B e C (Tabela 7 e Tabela 8) onde fica patente a quantidade de misturas que estariam indicadas erroneamente fora dos limites de trabalho (dados em vermelho). Todas as misturas foram concebidas com a mesma granulometria no centro da sua respetiva faixa, como supracitado. 
Tabela 7 - Análise granulométrica - Passante (\%) - Faixa B

\begin{tabular}{|c|c|c|c|c|c|c|c|c|c|c|c|}
\hline & Peneira & $11 / 2 "$ & $1 "$ & $3 / 4^{\prime \prime}$ & $3 / 8^{\prime \prime}$ & $n^{\circ} 4$ & $n^{\circ} 10$ & $n^{\circ} 40$ & $n^{\circ} 80$ & $n^{\circ} 200$ & $\begin{array}{l}\text { Vogt } \\
\left(m^{2} / \mathrm{kg}\right)\end{array}$ \\
\hline & $(\mathrm{mm})$ & 38,1 & 25,4 & 19,1 & 9,5 & 4,8 & 2 & 0,42 & 0,18 & 0,075 & \\
\hline & Projeto (\%) & 100 & 97,5 & 90 & 62,5 & 44 & 32,5 & 21 & 14 & 5,5 & 1130 \\
\hline & Limites (\%) & $\pm 7,0$ & $\pm 7,0$ & $\pm 7,0$ & $\pm 7,0$ & $\pm 5,0$ & $\pm 5,0$ & $\pm 5,0$ & $\pm 3,0$ & $\pm 2,0$ & ---- \\
\hline \multirow{3}{*}{$\begin{array}{l}\text { Santo Ant. } \\
\text { da Patrulha } \\
\text { (Diabásio) }\end{array}$} & 4,40 & 100,0 & 94,6 & 90,7 & 68,9 & 49,7 & 35,1 & 21,5 & 15,1 & 5,9 & 1136 \\
\hline & $4,90^{1}$ & 100,0 & 98,3 & 87,0 & 57,5 & 38,8 & 28,1 & 17,5 & 12,2 & 4,5 & 895 \\
\hline & 5,40 & 100,0 & 93,7 & 84,5 & 46,7 & 29,6 & 21,0 & 13,1 & 9,5 & 3,7 & 708 \\
\hline \multirow{3}{*}{$\begin{array}{l}\text { Santo Ant. } \\
\text { da Patrulha² } \\
\text { (Diabásio) }\end{array}$} & 4,30 & 100,0 & 97,8 & 90,0 & 62,2 & 43,6 & 29,7 & 18,8 & 13,4 & 5,6 & 1049 \\
\hline & $4,80^{1}$ & 100,0 & 97,7 & 89,1 & 59,5 & 40,7 & 27,0 & 16,9 & 12,0 & 4,8 & 921 \\
\hline & 5,30 & 100,0 & 92,4 & 86,5 & 55,4 & 37,1 & 25,3 & 15,7 & 11,0 & 4,4 & 851 \\
\hline \multirow{3}{*}{$\begin{array}{c}\text { Itaara } \\
\text { (Riodacito) }\end{array}$} & 5,40 & 100,0 & 96,9 & 92,1 & 66,5 & 47,6 & 34,5 & 20,8 & 16,1 & 5,6 & 1049 \\
\hline & $5,90^{1}$ & 100,0 & 98,2 & 94,4 & 63,5 & 42,1 & 29,4 & 17,0 & 12,4 & 3,9 & 921 \\
\hline & 6,40 & 100,0 & 96,0 & 88,2 & 53,1 & 34,7 & 25,0 & 14,5 & 11,0 & 3,5 & 851 \\
\hline \multirow{3}{*}{$\begin{array}{l}\text { Sarandi } \\
\text { (Diabásio) }\end{array}$} & 4,60 & 100,0 & 96,5 & 87,1 & 58,6 & 38,0 & 27,6 & 15,8 & 11,5 & 4,1 & 1107 \\
\hline & $5,10^{1}$ & 100,0 & 93,0 & 87,0 & 52,5 & 32,6 & 23,5 & 13,2 & 9,4 & 3,3 & 806 \\
\hline & 5,60 & 100,0 & 96,0 & 82,8 & 40,1 & 26,5 & 19,2 & 10,9 & 7,6 & 2,6 & 713 \\
\hline \multirow{3}{*}{$\begin{array}{l}\text { Eldorado } \\
\text { (Metasieno } \\
\text { Granito) }\end{array}$} & 4,90 & 100,0 & 97,0 & 92,5 & 69,2 & 43,3 & 30,3 & 20,1 & 13,1 & 5,4 & 800 \\
\hline & $5,40^{1}$ & 100,0 & 95,7 & 85,6 & 59,8 & 37,1 & 25,5 & 16,6 & 10,7 & 4,5 & 668 \\
\hline & 5,90 & 100,0 & 99,2 & 90,7 & 61,1 & 37,3 & 25,6 & 16,5 & 10,6 & 4,3 & 541 \\
\hline \multirow{3}{*}{$\begin{array}{l}\text { Pelotas } \\
\text { (Sieno } \\
\text { Granito) }\end{array}$} & 4,80 & 100,0 & 97,3 & 88,9 & 49,4 & 32,7 & 23,1 & 13,0 & 8,8 & 3,3 & 1031 \\
\hline & $5,30^{1}$ & 100,0 & 96,4 & 78,8 & 44,3 & 29,2 & 20,7 & 11,1 & 7,3 & 2,3 & 851 \\
\hline & 5,80 & 100,0 & 91,5 & 79,2 & 43,9 & 28,2 & 18,7 & 10,2 & 6,7 & 2,3 & 814 \\
\hline \multirow{3}{*}{$\begin{array}{l}\text { Caçapava } \\
\text { (Mármore } \\
\text { Dolomítico) }\end{array}$} & 4,60 & 100,0 & 96,2 & 86,9 & 57,2 & 36,5 & 27,7 & 17,9 & 12,0 & 5,7 & 648 \\
\hline & $5,10^{1}$ & 100,0 & 96,3 & 85,7 & 52,2 & 32,9 & 24,6 & 15,7 & 10,8 & 5,0 & 506 \\
\hline & 5,60 & 100,0 & 89,1 & 68,8 & 37,2 & 24,3 & 18,7 & 11,8 & 7,9 & 3,6 & 486 \\
\hline
\end{tabular}

Tabela 8 - Análise granulométrica - Passante (\%) - Faixa C

\begin{tabular}{|c|c|c|c|c|c|c|c|c|c|c|}
\hline & Peneira & $3 / 4^{\prime \prime}$ & $1 / 2^{\prime \prime}$ & $3 / 8^{\prime \prime}$ & $n^{\circ} 4$ & $n^{\circ} 10$ & $n^{\circ} 40$ & $n^{\circ} 80$ & $n^{\circ} 200$ & Vogt \\
\hline & $(\mathrm{mm})$ & 19,1 & 12,7 & 9,5 & 4,8 & 2 & 0,42 & 0,18 & 0,075 & $\left(\mathrm{~m}^{2} / \mathrm{kg}\right)$ \\
\hline & Projeto (\%) & 100,0 & 90,0 & 80,0 & 58,0 & 36,0 & 17,0 & 10,0 & 6,0 & 1040 \\
\hline & Limites (\%) & $\pm 7,0$ & $\pm 7,0$ & $\pm 7,0$ & $\pm 5,0$ & $\pm 5,0$ & $\pm 5,0$ & $\pm 3,0$ & $\pm 2,0$ & ---- \\
\hline \multirow{3}{*}{$\begin{array}{l}\text { Santo Ant. } \\
\text { da Patrulha } \\
\text { (Diabásio) }\end{array}$} & 4,40 & 100,0 & 87,4 & 83,8 & 63,3 & 33,4 & 15,1 & 10,4 & 5,6 & 988 \\
\hline & $4,90^{1}$ & 100,0 & 83,2 & 77,4 & 54,9 & 29,4 & 13,6 & 9,6 & 5,3 & 921 \\
\hline & 5,40 & 100,0 & 78,1 & 70,5 & 47,4 & 25,1 & 11,5 & 8,1 & 4,3 & 761 \\
\hline \multirow{3}{*}{$\begin{array}{l}\text { Santo Ant. } \\
\text { da Patrulha² } \\
\text { (Diabásio) }\end{array}$} & 4,30 & 100,0 & 85,2 & 75,5 & 52,3 & 29,4 & 13,7 & 9,2 & 4,5 & 829 \\
\hline & $4,80^{1}$ & 100,0 & 85,0 & 76,6 & 52,2 & 27,1 & 12,6 & 8,2 & 3,7 & 712 \\
\hline & 5,30 & 100,0 & 82,5 & 73,3 & 50,9 & 27,5 & 12,5 & 7,9 & 3,9 & 716 \\
\hline \multirow{3}{*}{$\begin{array}{c}\text { Itaara } \\
\text { (Riodacito) }\end{array}$} & 5,40 & 100,0 & 88,6 & 78,7 & 59,0 & 37,0 & 16,4 & 12,1 & 5,6 & 829 \\
\hline & $5,90^{1}$ & 100,0 & 87,8 & 76,7 & 54,2 & 33,9 & 15,1 & 10,9 & 4,8 & 712 \\
\hline & 6,40 & 100,0 & 80,6 & 69,7 & 49,5 & 30,2 & 13,0 & 9,4 & 4,2 & 716 \\
\hline \multirow{3}{*}{$\begin{array}{l}\text { Sarandi } \\
\text { (Diabásio) }\end{array}$} & 4,60 & 100,0 & 88,0 & 76,5 & 52,1 & 28,2 & 12,2 & 7,9 & 4,0 & 1024 \\
\hline & $5,10^{1}$ & 100,0 & 83,9 & 73,4 & 49,9 & 26,5 & 10,8 & 6,6 & 3,0 & 913 \\
\hline & 5,60 & 100,0 & 83,5 & 71,3 & 46,8 & 25,1 & 10,1 & 6,4 & 3,0 & 789 \\
\hline \multirow{3}{*}{$\begin{array}{c}\text { Eldorado } \\
\text { (Metasieno } \\
\text { Granito) } \\
\end{array}$} & 4,90 & 100,0 & 87,3 & 76,6 & 54,2 & 32,0 & 14,9 & 9,3 & 5,4 & 727 \\
\hline & $5,40^{1}$ & 100,0 & 88,5 & 76,7 & 54,1 & 31,2 & 13,6 & 8,6 & 4,7 & 594 \\
\hline & 5,90 & 100,0 & 90,7 & 78,3 & 55,3 & 31,0 & 13,5 & 8,3 & 4,4 & 570 \\
\hline \multirow{3}{*}{$\begin{array}{c}\text { Pelotas } \\
\text { (Sieno } \\
\text { Granito) }\end{array}$} & 4,80 & 100,0 & 82,9 & 71,1 & 46,4 & 29,0 & 11,6 & 7,1 & 3,4 & 943 \\
\hline & $5,30^{1}$ & 100,0 & 84,6 & 75,3 & 51,5 & 30,6 & 11,8 & 7,2 & 3,5 & 846 \\
\hline & 5,80 & 100,0 & 77,4 & 63,3 & 41,5 & 25,1 & 9,3 & 5,6 & 2,6 & 819 \\
\hline \multirow{3}{*}{$\begin{array}{l}\text { Caçapava } \\
\text { (Mármore } \\
\text { Dolomítico) }\end{array}$} & 4,60 & 100,0 & 80,8 & 69,9 & 46,5 & 29,9 & 14,0 & 8,7 & 5,1 & 655 \\
\hline & $5,10^{1}$ & 100,0 & 77,9 & 65,9 & 42,5 & 27,5 & 12,5 & 7,7 & 4,3 & 664 \\
\hline & 5,60 & 100,0 & 77,3 & 65,5 & 44,0 & 27,8 & 12,6 & 7,7 & 4,2 & 519 \\
\hline
\end{tabular}

${ }^{1}$ Misturas com teor de projeto

${ }^{2}$ Misturas com AMP 60/85-E SBS 
As curvas médias de Santo Antônio da Patrulha, exemplificadas na Figura 6.a e Figura 6.b, mostram o comportamento típico dos dados da centrífuga encontrados nas diferentes rochas nos 3 teores aplicados. Nestas curvas, a medida que o teor de ligante se eleva, diminui-se a eficiência da extração, proporcionando curvas mais grossas. Esse comportamento pode ser visto com a diminuição dos valores de superfície específica, demonstradas através do EAM do número de Vogt (Figura 6.c e Figura 6.d), sendo esta uma metodologia de cálculo de superfície específica. Ainda, nota-se que todas as misturas apresentaram valores de superfície específica abaixo do valor de projeto.

0 comportamento relatado se mostra condizente com o que foi visto na análise realizada para a obtenção do teor de ligante, já que o ligante não extraído acabou por distorcer as curvas granulométricas por ainda haver aglutinamento de partículas de agregados. Estes aglomerados de partículas com ligante acabaram por se depositar em peneiras mais grossas erroneamente (Figura 7) a ponto de deslocar as curvas para fora do limite de trabalho nas misturas com maior quantidade de ligante.

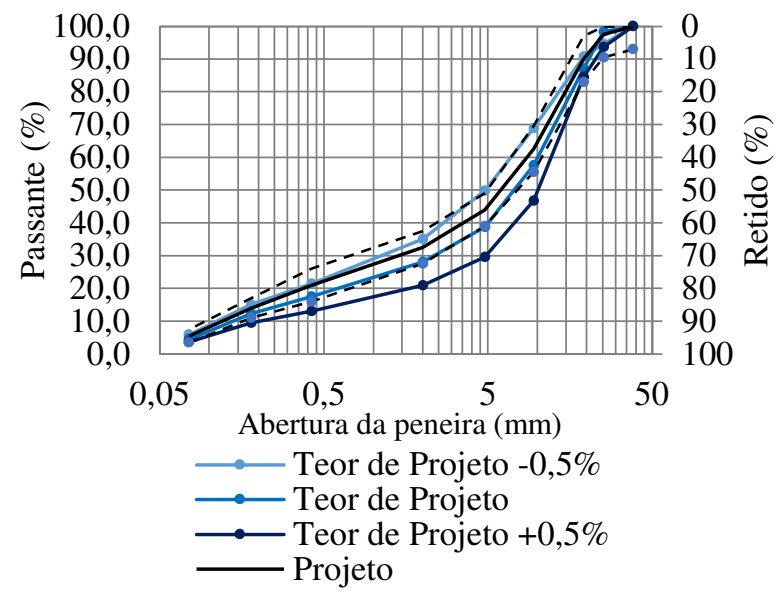

a) St. Antônio da Patrulha - Faixa B

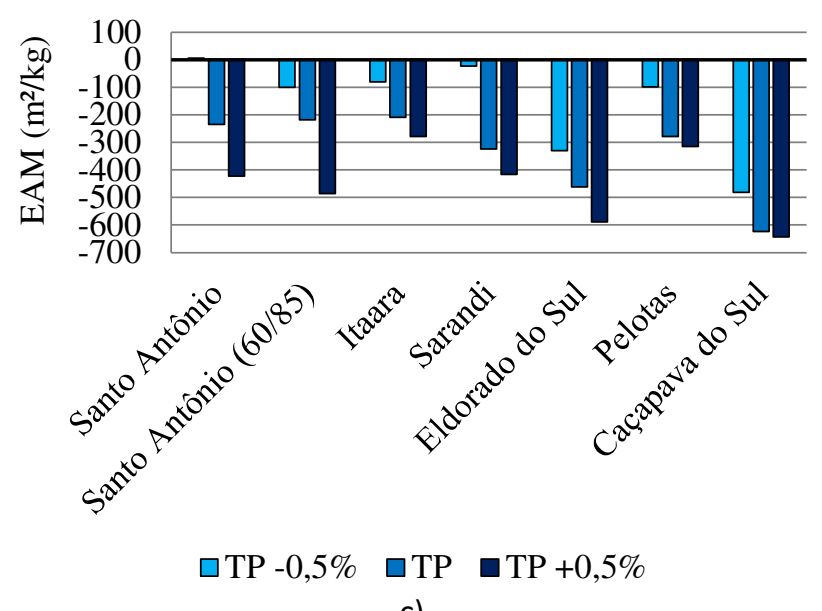

c)

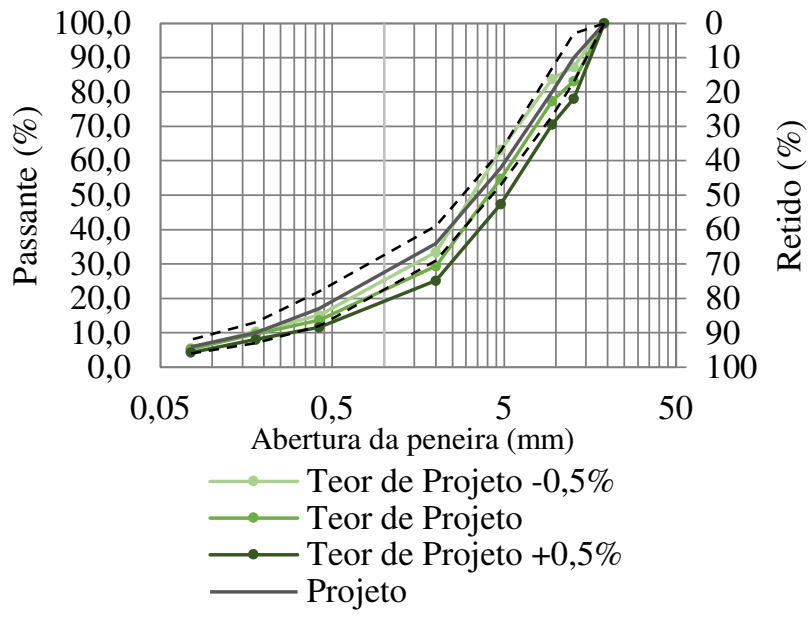

b) St. Antônio da Patrulha - Faixa C

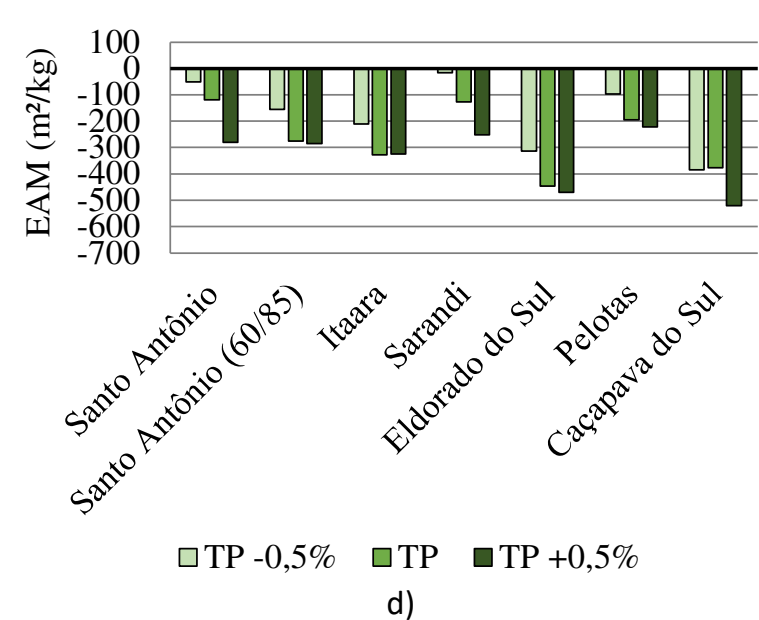

d)

Figura 6. Curvas médias por teor de ligante faixa B (a) e C (b) e EAM do Vogt por mistura faixa B (c) e C (d)

A combinação dos equívocos no controle de teor de ligante e granulometria acabaria por distorcer totalmente o controle tecnológico. Uma mistura com teor de ligante superior em 0,5\% daquele de projeto apresentaria um teor de controle tecnológico aparentemente próximo ao 
teor de projeto, Por exemplo. Porém sua curva granulométrica poderia se apresentar próxima ao limite de trabalho, avaliando positivamente uma mistura que na realidade está fora do teor de projeto, mas com uma correta granulometria.

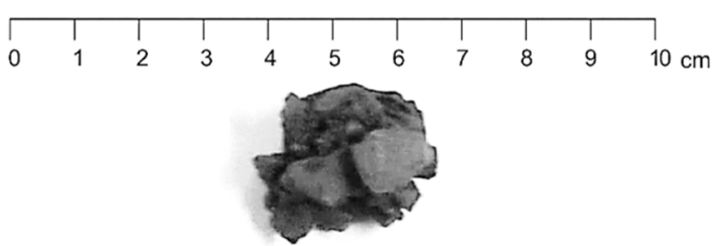

Figura 7. Exemplos de material acumulado na peneira $3 / 8^{\prime \prime}$

A Tabela 9 apresenta a ANOVA aplicada aos dados de EAM da granulometria nas faixas B e C utilizadas no trabalho. Tanto na faixa $B$ quanto na $C$, a centrífuga se mostra influenciada diretamente pela variação de rochas, teor de ligante e tipo de ligante. Assim como ocorrera na análise de variância do teor de ligante, deve-se reforçar que a centrífuga deveria ter apresentado resultados menos sensíveis às variações impostas neste estudo, a fim de que conseguisse trazer maior credibilidade ao controle tecnológico de misturas asfálticas, reproduzindo fidedignamente os parâmetros elementares deste material.

Tabela 9 - ANOVA aplicado ao EAM dos dados de granulometria - Comparação entre faixas

\begin{tabular}{|c|c|c|c|c|c|c|c|}
\hline & \multirow[b]{2}{*}{$g l$} & \multicolumn{3}{|c|}{ Faixa B } & \multicolumn{3}{|c|}{ Faixa C } \\
\hline & & $\boldsymbol{F}$ & $p$ & Sig. ${ }^{1}$ & $\boldsymbol{F}$ & $p$ & Sig. ${ }^{1}$ \\
\hline Rochas & 5 & 12,841 & 0,000 & $S$ & 8,576 & 0,000 & $S$ \\
\hline Teor de ligante & 2 & 25,276 & 0,000 & $S$ & 17,187 & 0,000 & $S$ \\
\hline Tipo de ligante & 1 & 5,636 & 0,023 & $s$ & 14,476 & 0,001 & $S$ \\
\hline
\end{tabular}

\section{CONCLUSÕES}

Dentre as principais conclusões da pesquisa, destacam-se:

- Os teores de ligante obtidos através da centrífuga nessa pesquisa revelaram uma baixa confiabilidade. Os valores de desvio padrão e erro absoluto médio extrapolaram o limite de $0,3 \%$ de variação de teor de ligante do DNIT para produção de concretos asfálticos, colocando em dúvida a centrífuga como metodologia a ser utilizada em controle de produção e qualidade. 0 erro absoluto médio da obtenção de teor de ligante se mostrou inversamente proporcional ao teor empregado na mistura, impossibilitando um fator de correção para calibração. Esses erros da centrífuga e a alta dispersão estão diretamente ligados à sua extração ineficiente do ligante asfáltico com uma alta sensibilidade dos seus dados;

- A análise granulométrica foi igualmente influenciada pela extração incompleta do ligante pela centrífuga, onde o acúmulo de material fino junto ao ligante não extraído em peneiras mais grossas provocou distorções nas curvas granulométricas. Em várias misturas as curvas extrapolaram equivocadamente os limites de trabalho.

Frente aos avanços tecnológicos em dosagem de concretos asfálticos e acompanhando o novo método de dimensionamento de pavimentos no Brasil, deve-se buscar uma metodologia eficaz e confiável para garantiar que todo o empenho na fase de projeto seja aplicado e garantido em pista. Essa garantia só é possível com um controle tecnológico condizente com esses avanços. 
Portanto, a norma DNER-ME 053/94, ao ser empregada como descrito em sua metodologia, dentro da ampla matriz fatorial avaliada neste estudo, mostrou-se ineficiente para a determinação de teor de ligante e granulometria. Esses sendo parâmetros essenciais à garantia de adequado desempenho dos revestimentos asfálticos em campo.

\section{AGRADECIMENTOS}

Os autores agradecem à FAPERGS, CAPES e CNPQ pelas bolsas e à ANP/PETROBRAS pelo suporte financeiro que possibilitou a infraestrutura laboratorial, no âmbito da Rede Temática do Asfalto.

\section{REFERÊNCIAS}

ABNT (2001) NBR 30 - Agregado miúdo - Determinação da absorção de água. Associação Brasileira de Normas Técnicas, Rio de Janeiro, RJ.

ABNT (2012) NBR 6296 - Produtos betuminosos semissólidos - Determinação da massa específica e densidade relativa. Associação Brasileira de Normas Técnicas, Rio de Janeiro, RJ.

ABNT (2016) NBR 6560 - Ligantes asfálticos - Determinação do ponto de amolecimento - Método do anel e bola. Associação Brasileira de Normas Técnicas, Rio de Janeiro, RJ.

ABNT (2007) NBR 6576 - Materiais asfálticos - Determinação de penetração. Associação Brasileira de Normas Técnicas, Rio de Janeiro, RJ.

ABNT (2014) NBR 11341 - Derivados de petróleo - Determinação dos pontos de fulgor e de combustão em vaso aberto Cleveland. Associação Brasileira de Normas Técnicas, Rio de Janeiro, RJ.

ABNT (2006) NBR 15086 - Materiais betuminosos - Determinação da recuperação elástica pelo ductômetro. Associação Brasileira de Normas Técnicas, Rio de Janeiro, RJ.

ABNT (2004) NBR 15184 - Materiais betuminosos - Determinação da viscosidade em temperaturas elevadas usando um viscosímetro rotacional. Associação Brasileira de Normas Técnicas, Rio de Janeiro, RJ.

ABNT (2014) NBR 16273 - Misturas asfálticas - Propriedades volumétricas de concreto asfáltico. Associação Brasileira de Normas Técnicas, Rio de Janeiro, RJ.

ATSDR (2014) Toxicological Profile for Trichloroethylene. Agency for Toxic Substances and Disease Registry, Department of Health and Human Services. Atlanta, GA.

AASHTO (1986) T 164-86 - Quantitative extraction of bitumen from bituminous paving mixtures. American Association of State Highway and Transportation Officials, Washington, DC.

ASTM (1975) D 2172 - Quantitative extraction of bitumen from bituminous paving mixtures. American Society for Testing and Materials, West Conshohocken, PA.

ASTM (2017) D 2172 - Quantitative extraction of bitumen from bituminous paving mixtures. American Society for Testing and Materials, West Conshohocken, PA.

ASTM (2016) D 3666 - Standard Specifification for Minimum Requirements for Agencies Testing and Inspecting Road and Paving Materials. American Society for Testing and Materials, West Conshohocken, PA.

BERNUCCI, L. B.; L. M. G. da MOTTA; J. A. P. CERATTI e J. B. SOARES (2006) Pavimentação Asfáltica: Formação Básica para Engenheiros. 504 p. Petrobras: Abeda, Rio de Janeiro, RJ. DOI: 10.13140/2.1.4361.5684

BOHN, K. A. (2017) Avaliação de misturas asfálticas recicladas mornas com uso de ligantes convencional e modificado por polímero. 254 p. Dissertação (Mestrado em Engenharia Civil), Universidade Federal de Santa Maria, Santa Maria, RS.

BROWN, E. R.; N. MURPHY; L. YU e S. MAGER (1995) Historical Development of Asphalt Content Determination by the Ignition Method. NCAT Report 95-02. 28 p. National Center for Asphalt Technology. Alabama Department of Transportation, Auburn, AL.

BURATI, J. L.; R. M. WEED; C. S. HUGHES e H. S. HILL (2003) Optimal Procedures for Quality Assurance Specifications. 347 p. Office of Research, Development, and Technology. Federal Highway Administration FHWA-RD-02-095. McLean, VA.

BURR, B. L.; R. R. DAVISON; C. J. GLOVER e J. A. BULLIN (1990) Solvent Removal from Asphalt. Transportation Research Record 1269. Department of Chemical Engineering and Texas Transportation Institute. Texas A\&M University. College Station, TX.

BURR, B. L.; R. R. DAVISON; H. B. JEMISON; C. J. GLOVER e J. A. BULLIN (1990) Asphalt Hardening in Extraction Solvents. Transportation Research Record 1323, p. 70-76. Department of Chemical Engineering and Texas Transportation Institute, Texas A\&M University, College Station, TX

BUTTS, N. e K. KSAIBATI (2003) Evaluating the Impact of QC/QA Programs on Asphalt Mixture Variability. 151 p. Department of Civil and Architectural Engineering, University of Wyoming, Laramie, WY.

CERATTI, J. A. P. e R. M. M. REIS (2011) Manual de Dosagem de Concreto Asfáltico. Oficina de Textos, 152 p. São Paulo, SP.

CIPIONE, C. A.; R. R. DAVISON; B. L. BURR; C. J. GLOVER e J. A. BULLIN (1991) Evaluation of Solvents for Extraction of Residual Asphalt from Aggregates. Transportation Research Record 1323, p. 47-52. Department of Chemical Engineering and Texas Transportation Institute. Texas A\&M University. College Station, TX.

COLLINS-GARCIA, H.; M. TIA; R. ROQUE e B. CHOUBANE (2000) An evaluation of an alternative solvent extraction of asphalt to reduce health and enviornmental hazards. 18 p. Transportation Reasearch Board, Washington, DC. DOI: 10.3141/1712-10 
COMINSKY, R. J.; B. M. KILLINGSWORTH; R. M. ANDERSON; D. A. ANDERSON e W. W. CROCKFORD (1998) Quality Control and Acceptance of Superpave-Designed Hot Mix Asphalt. 215 p. NCHRP Report 409. National Academy Press. Washington, DC.

DNER (1998) ME 035 - Agregados - Determinação da abrasão “Los Angeles”. Departamento Nacional de Estradas de Rodagem. Rio de Janeiro, RJ.

DNER (1994) ME 053 - Misturas Betuminosas - percentagem de betume. Departamento Nacional de Estradas de Rodagem. Rio de Janeiro, RJ.

DNER (1998) ME 083 - Agregado - análise granulométrica. Departamento Nacional de Estradas de Rodagem. Rio de Janeiro, RJ.

DNER (1994) ME 089 - Agregados - Avaliação da durabilidade pelo emprego de soluções de sulfato sulfato de sódio ou de magnésio. Departamento Nacional de Estradas de Rodagem. Rio de Janeiro, RJ.

DNER (1997) ME 195 - Agregados - determinação da absorção e da massa específica de agregado graúdo. Departamento Nacional de Estradas de Rodagem. Rio de Janeiro, RJ.

DNER (2006) 031-ES - Pavimentos flexíveis - Concreto asfáltico - Especificação de serviço. Departamento Nacional de Estradas de Rodagem. Rio de Janeiro, RJ.

DNIT (2006) 031 - Manual de Pavimentação. Departamento Nacional de Infraestrutura de Transportes. IPR1994. Rio de Janeiro, RJ.

DNIT (2019) Método de ensaio - ME. Departamento Nacional de Infraestrutura de Transportes. Disponível em: <http://ipr.dnit.gov.br/normas-e-manuais/normas/meetodo-de-ensaio-me>. Acesso em: 25 de abril de 2019.

DNIT (2011) 158/2011 ME - Mistura asfáltica - Determinação da porcentagem de betume em mistura asfáltica utilizando o extrator Soxhlet - Método de ensaio. Departamento Nacional de Infraestrutura de Transportes. Rio de Janeiro, RJ.

GLOVER, C. J.; R. R. DAVISON; S. M. GHOREISHI; H. B. JEMISON e J. A. BULLIN (1989) Evaluation of Oven Simulation of Hot-Mix Aging by an FT-IR Pellet Procedure and Other Methods. Transportation Research Record 1228, p. 177-182. Department of Chemical Engineering and Texas Transportation Institute, Texas A\&M University, College Station, TX

HALL, K. D. e S. G. WILLIAMS (1998) Effects of the Ignition Method on Aggregate Properties. Journal of the Association of Asphalt Paving Technologists v. 68, p. 574-588. Annual Meeting of the Association of Asphalt Paving Technologists. Chicago, IL.

HARVEY, J. T.; J. A. DEACON; B. TSAI e C. L. MONISMITH (1995) Fatigue performance of asphalt concrete mixes and its relationship to asphalt concrete pavement performance in California. RTA-65W485-2, $189 \mathrm{f}$. Institute of Transportation Studies. University of California at Berkeley, Berkeley, CA.

MEDINA, J. e L. M. G. MOTTA (2015) Mecânica dos Pavimentos. 3a ed. Editora UFRJ, 640 p. Rio de Janeiro, RJ.

NOGUEIRA, M. L. (2011) Avaliação do controle de qualidade de misturas asfálticas e análise do reflexo do nível de qualidade no desempenho dos revestimentos asfálticos. 88 p. Dissertação (Mestrado em Engenharia Civil). Universidade Federal do Rio Grande do Sul, Porto Alegre, RS.

PAPAGIANNAKIS, A. T. e E. A. MASAD (2008) Pavement Design and Materials. 544 p. John Wiley \& Sons, Inc. Hoboken, NJ.

PLANCHER, H.; S. M. DORRENCE e J. C. PETERSEN (1977) Identification of chemical types in asphalts strongly adsorbed at the asphalt-aggregate interface and their relative displacement by water. 34 p. Annual meeting of the Association of Asphalt Paving Technologists. San Antonio, TX.

PETERSEN, J. C. (1982) Relationships between asphalt chemical composition and performance related properties. Ninth Annual Meeting of the Asphalt Emulsion Manufacturers Association, Las Vegas, NV.

PETERSEN, J. C. (2000) Chapter 14: Chemical Composition of Asphalt as Related to Asphalt Durability. Asphaltenes and Asphalts, v. 2, p. 363-399. DOI:10.1016/s0376-7361(09)70285-7

PETERSEN, J. C.; E. K. ENSLEY e F. A. BABOUR (1974) Molecular interaction of asphalt in the asphalt-aggregate interface region. Transportation Research Record 515, p. 67-78. National Research Council, Washington, DC.

TRAXLER, R. N. (1967) Changes in asphalt cements during preparation laying and service of bituminous pavements. Texas Transportation Researcher v. 3, n. 1. Texas Transportation Institute, Texas A\&M University, College Station, TX.

YODER, E. J. e M. W. WITCZAK (1975) Principles of pavement design. 716 p. $2^{\text {a }}$ ed. John Wiley \& Sons, Inc. DOI: $10.1002 / 9780470172919$.

WHO (1989) IARC Monographs on the evaluation of carcinogenic risks to humans: v. 47: some organic solvents, resin monomers and related compounds, pigments and occupational exposures in paint manufacture and painting. 544 p. IARC Press. International Agency for Research on Cancer. World Health Organization. Lyon, França. 